\title{
Bioclimatic Modeling of the Potential Distribution of the Western Tien-Shan Endemic Tulipa kaufmanniana Regel (Uzbekistan, Kazakhstan)
}

\author{
Bekzod J. Mavlanov, Ozodbek S. Abduraimov, Azizbek V. Mahmudov, \\ Akmal L. Allamuratov, Odilbek T. Mamatkosimov \\ Institute of Botany Academy Sciences Republic of Uzbekistan, Tashkent, Uzbekistan \\ Email: mavlanov.bekzod@mail.ru
}

How to cite this paper: Mavlanov, B.J., Abduraimov, O.S., Mahmudov, A.V., Allamuratov, A.L. and Mamatkosimov, O.T. (2021) Bioclimatic Modeling of the Potential Distribution of the Western Tien-Shan Endemic Tulipa kaufmanniana Regel (Uzbekistan, Kazakhstan). American Journal of Plant Sciences, 12, 1468-1477.

https://doi.org/10.4236/ajps.2021.1210104

Received: September 3, 2021

Accepted: October 15, 2021

Published: October 18, 2021

Copyright $(02021$ by author(s) and Scientific Research Publishing Inc. This work is licensed under the Creative Commons Attribution International License (CC BY 4.0).

http://creativecommons.org/licenses/by/4.0/

\begin{abstract}
The article analyzes the natural distribution area of the species Tulipa kaufmanniana Regel using the programs of type MaxEnt and ArcGis, the endemic of Central Asia (past, current, future). According to the results of the study, it is proved that the main distribution of the species coincides with the boundaries of the areali Tien-Shan mountain system (Uzbekistan, Kazakhstan). It is noted that the climatic factors that are optimal for the species are sufficient temperature and annual precipitation.
\end{abstract}

\section{Keywords}

T. kaufmanniana Regel, Tien-Shan, Endemic, Modeling, TASH, MaxEnt, Uzbekistan, Kazakhstan

\section{Introduction}

The Central Asian region is one of the centers of origin of the species Tulipa L. [1] [2] [3]. Tulipa L. has a vast habitat throughout Eurasia, extending from the northern regions of Portugal and Africa to the west, southeast to the islands of Japan [4]. Most of the world's most exquisitely cultivated tulips are native to Central Asia. About 70 species of the genus grow in Central Asia, more than half of which are considered as endemic [5] [6] [7]. There are 34 species of the genus in Uzbekistan, 37 species in Kazakhstan, 22 species in Kyrgyzstan, 24 species in Tajikistan and 16 species in Turkmenistan [8] [9].

Tulipa kaufmanniana Regel in Tashkent and Namangan regions: grows soli- 
tary or in small tufts on rocky soils from the foothills to the upper parts of (lower part of the pasture) Ugom, Piskom, Qorjantov, Chatkal, Qurama ridges and is considered a declining endemic plant in Western Tien Shan, therefore included in the Red Data Book with the $3^{\text {rd }}$ status [10]. Today, as a result of global climate change, especially the sharp rise in air temperature it is important to assess and to conduct regular monitoring of the current state of rare and endangered species in the world. At the same time, there is an increase in anthropogenic impacts on plant communities and rare plants.

In this article, the potential distribution area of $T$. kaufmanniana Regel, which is rare for the flora of Central Asia, is also modeled over several periods (low, current and future) in order to determine the impact of climate change on the species population. These analyses were performed on the basis of samples stored in the National Herbarium Fund (TASH), international GBIF data and the results of field research.

The results of field studies show that the representatives of the genus are spring ephemeroids with a very short growing season. The vegetation period of the representatives of the genus is 120 - 140 days. The object of study $T$. kaufmanniana Regel was scientifically described in 1877 by E. Regel. One of the unique features of the species is its widespread use in selection work. The world-famous Dutch tulips are the descendants of T. kaufmanniana Regel (Figure $1)$.

In recent years, the use of modern methods in the analysis of botanical research has also become a tradition. In particular, a number of studies have been conducted on the population of species and the prediction of their habitats. One such method is the modern MaxEnt (Maximal Entropy) program.

\section{Material and Methods}

The object of study is T. kaufmanniana Regel. Predictive analyzes were performed on the basis of samples taken from the database of the National Herbarium (TASH) of the Institute of Botany of the Academy of Sciences of the Republic of Uzbekistan and the Global Biodiversity Information Facility (GBIF, https://www.gbif.org/) [11-12].

MaxEnt method was studied by S.J. Phillips et al., [13] [14] and is now one of the most effective methods in modeling species distribution. This method is based on the creation of a generalized climate envelope using the climatic data of the points about where the species is recorded. BIOCLIM was developed by $\mathrm{H}$. Nix and is widely used to create a climate profile of species and determine their potential habitats.

\section{Result and Discussion}

To date, Tulipa L. in Uzbekistan a lot of research has been carried out on the study of types of cenopopulations [15] [16]. A total of 96 points were obtained on the basis of TASH and GBIF data in the analysis (Table 1). 

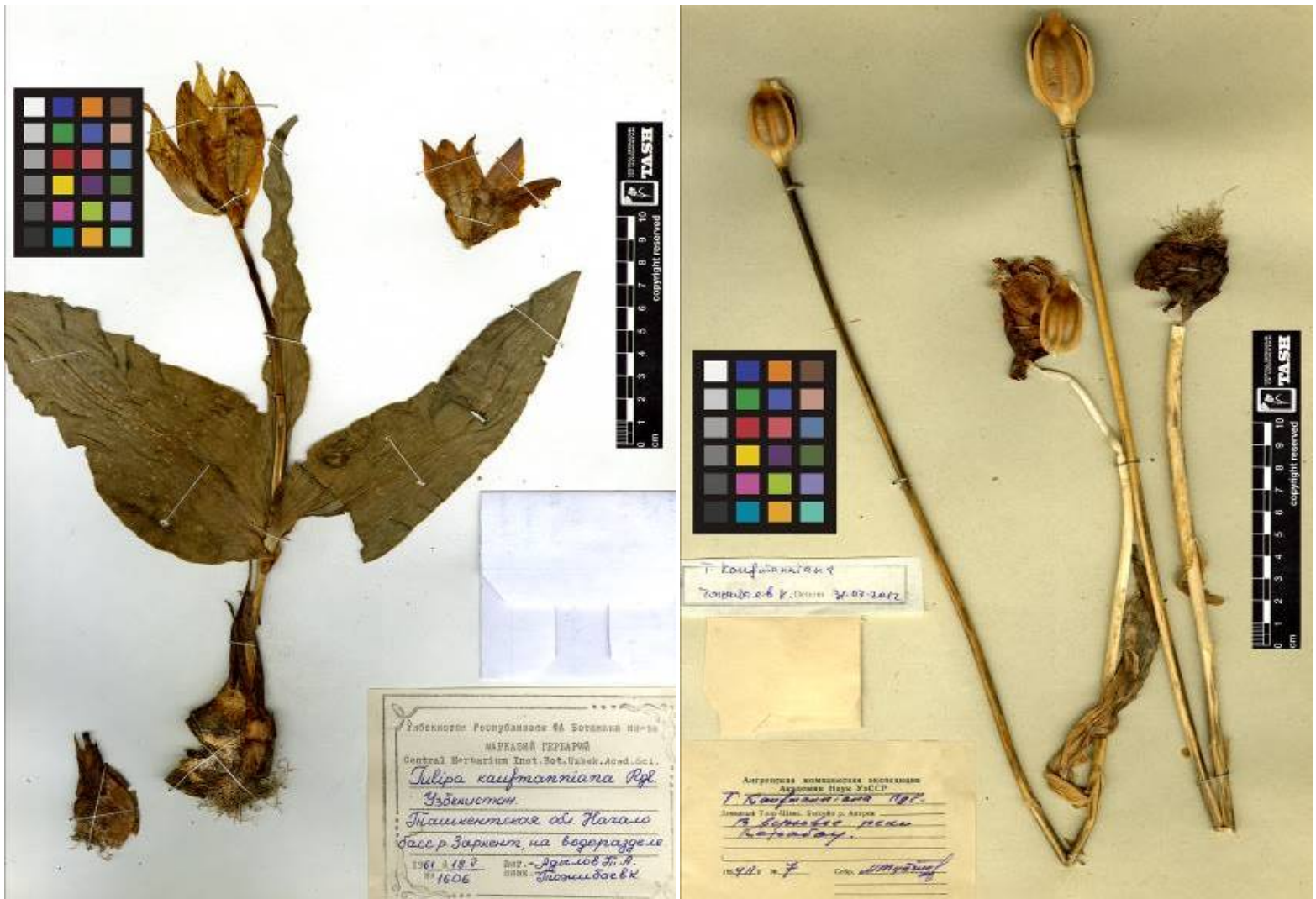

(a)
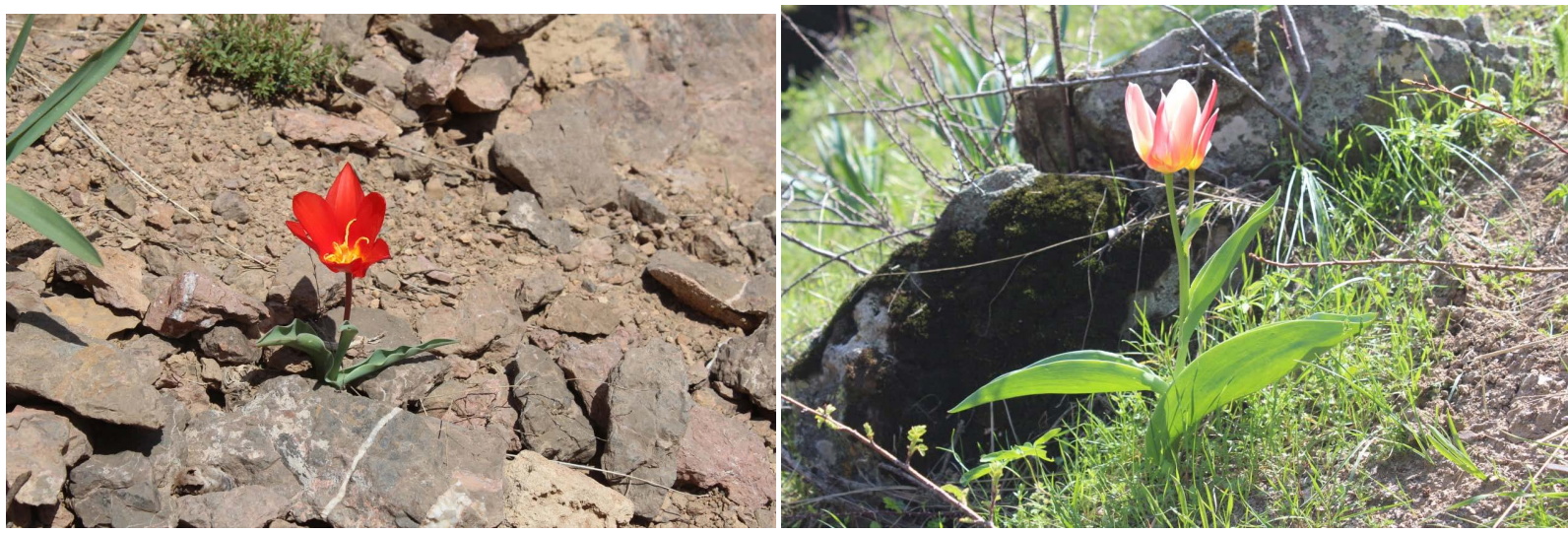

(b)

Figure 1. T. kaufmanniana in different conditions. (a) National herbarium (TASH); (b) Natural populations.

Table 1. Number of herbarium specimens and sources from which they were obtained.

\begin{tabular}{cccc}
\hline Ridge & Administrative territories & Number of coordinates & Sources of information \\
\hline \multirow{2}{*}{ Tien-Shan } & Uzbekistan & 87 & TASH \\
& Kazakhstan & 9 & GBIF \\
\hline
\end{tabular}

From the points it can be seen that the main distribution are of the species is an important criterion in the prediction of endemic species and in the development of strategies to reduce this risk (Figure 2). 


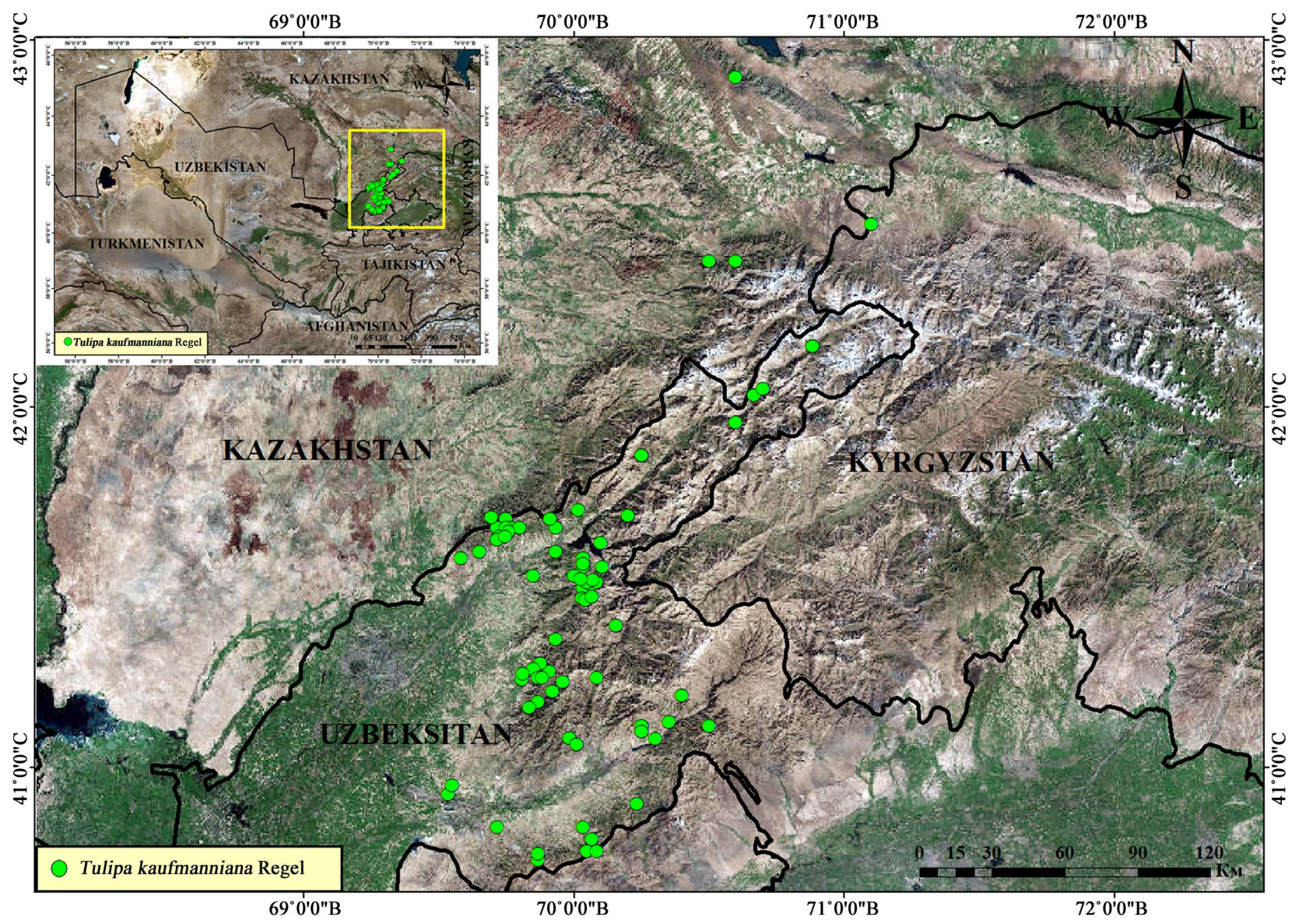

Figure 2. The natural distribution area of the species.

Climate change is one of the main factors affecting the range of the species, and international government experts have noted that the average global temperature will rise by $1.4^{\circ} \mathrm{C}-5.8^{\circ} \mathrm{C}$ between 1900 and 2100 . Today, climate change is having an impact on species adaptation and development. In the coming years, species modeling analyzes will play an important role in current and future analyzes. The developed models play a crucial role in predicting the risk of future biodiversity loss and in shifting strategies to reduce this risk. Prediction of species distribution areas for high-probability climate scenarios is based on MaxEnt and 19 BIOCLIM (Table 2) trends from World Clim 2.1 (https://www.worldclim.org/) [17].

When performing analyses using each method, specific criteria are important. In particular, during the study, growth coefficient of the modeling results of the species was defined from 0 to 1 . In this appendix, the high range of the species is described in "red", the areas with low distribution are described in "yellow", the areas with low probability of distribution and almost no chance of occurrence are described in "light and dark blue". Other colors have an average rating (Figure 3).

According to the spread of climate change scenarios in PAST - in the recent past (1970-2000), Current-in the present and Future-in the future SSPs585 (2050) region with convenient climatic conditions for optimal growth of the $T$. kaufmanniana Regel can be seen in the Western Tien Shan. It is and endemic 
Table 2. Trends in bioclimatic variability.

\begin{tabular}{ccc}
\hline Bio 1 & Annual mean temperature & ${ }^{\circ} \mathrm{C}$ \\
\hline Bio 2 & Mean diurnal range (max. Temp -min. temp) & ${ }^{\circ} \mathrm{C}$ \\
Bio 3 & Isothermality (Bio2/Bio7) $\times 100$ & \\
Bio 4 & Temperature seasonality (SD $\times 100)$ & ${ }^{\circ} \mathrm{C}$ \\
Bio 5 & Max temperature of warmest month & ${ }^{\circ} \mathrm{C}$ \\
Bio 6 & Min temperature of coldest month & ${ }^{\circ} \mathrm{C}$ \\
Bio 7 & Temperature annual range (Bio5-Bio6) & ${ }^{\circ} \mathrm{C}$ \\
Bio 8 & Mean temperature of wettest quarter & ${ }^{\circ} \mathrm{C}$ \\
Bio 9 & Mean temperature of driest quarter & ${ }^{\circ} \mathrm{C}$ \\
Bio 10 & Mean temperature of warmest quarter & ${ }^{\circ} \mathrm{C}$ \\
Bio 11 & Mean temperature of coldest quarter & ${ }^{\circ} \mathrm{C}$ \\
Bio 12 & Annual precipitation & $\mathrm{mm}$ \\
Bio 13 & Precipitation of wettest month & $\mathrm{mm}$ \\
Bio 14 & Precipitation of driest month & $\mathrm{mm}$ \\
Bio 15 & Precipitation seasonality (Coefficient of variation) & \\
Bio 16 & Precipitation of wettest quarter & $\mathrm{m}$ \\
Bio 17 & Precipitation of driest quarter & $\mathrm{mm}$ \\
Bio 18 & Precipitation of warmest quarter & $\mathrm{mm}$ \\
Bio 19 & Precipitation of coldest quarter & $\mathrm{mm}$ \\
Elev & Elevation & ${ }^{\circ}$ \\
\hline
\end{tabular}

\begin{tabular}{|l|}
$\square \quad 0.73-0.91$ \\
$\square \quad 0.58-0.73$ \\
$\square \quad 0.45-0.58$ \\
$\square \quad 0.33-0.45$ \\
$\square \quad 0.22-0.33$ \\
$\square \quad 0.13-0.22$ \\
$\square \quad 0.06-0.13$ \\
$\square \quad 0.01-0.06$ \\
$\square \quad 0.00-0.01$
\end{tabular}

Figure 3. Species growth coefficient.

species for the Western Tien-Shan ridge, causing large differences between its real and potential range. The Tian-Shan Range averages $707.7 \mathrm{~mm}$ of annual precipitation in the areas where the coordinates are available and the Tien-Shan region has the most favorable annual rainfall for the growth of this tournament between the ridges, corresponding to the optimal rainfall range.

Modeling the T. kaufmanniana Regel based on climatic scenarios and identifying new populations in areas where it may occur requires constant monitoring and regular targeted field research. Analysis of the natural distribution range of the species shows that the areas where the species can grow are based on the Tien Shan area and adjacent areas (Figure 4). According to the modeling results, 

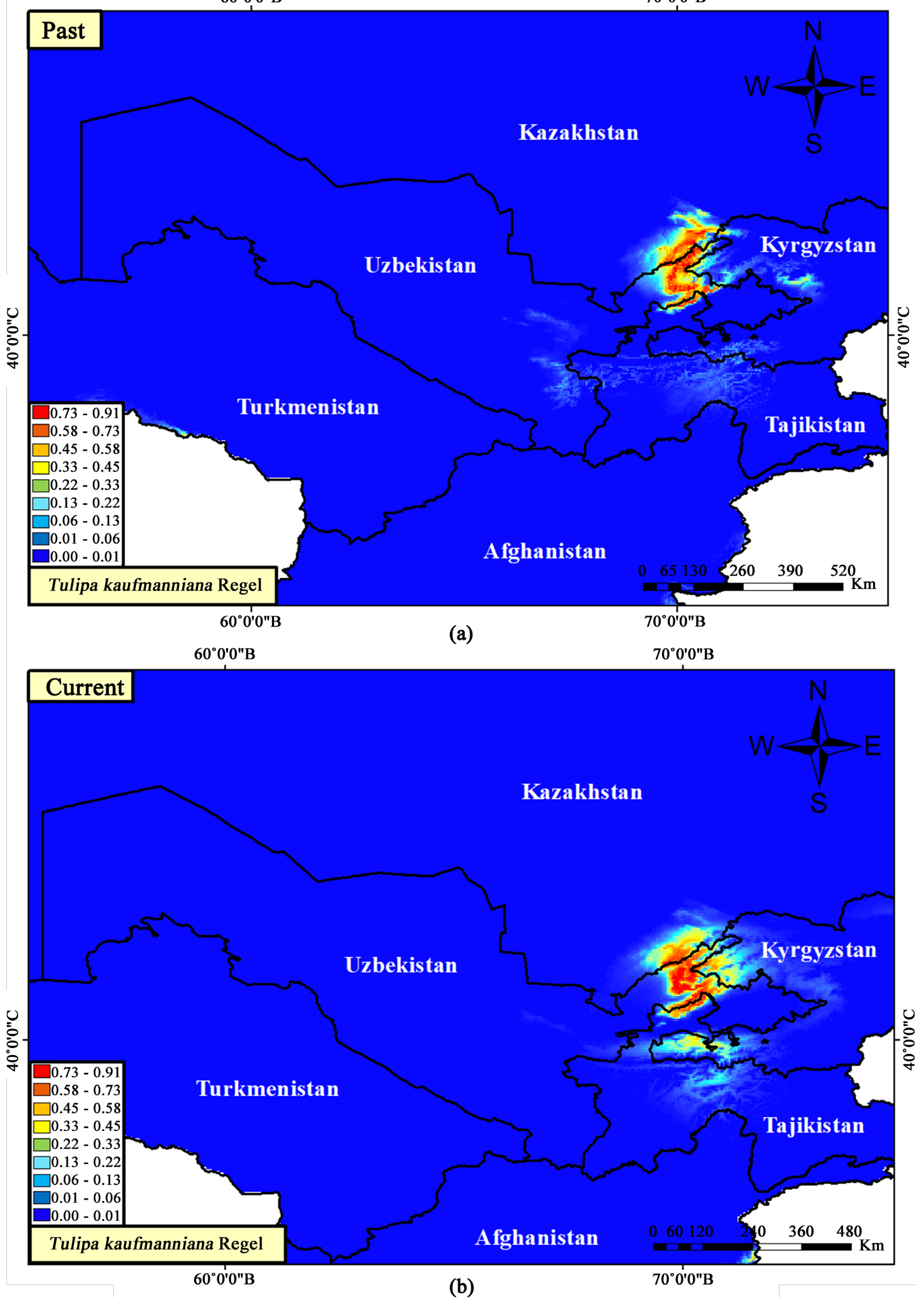


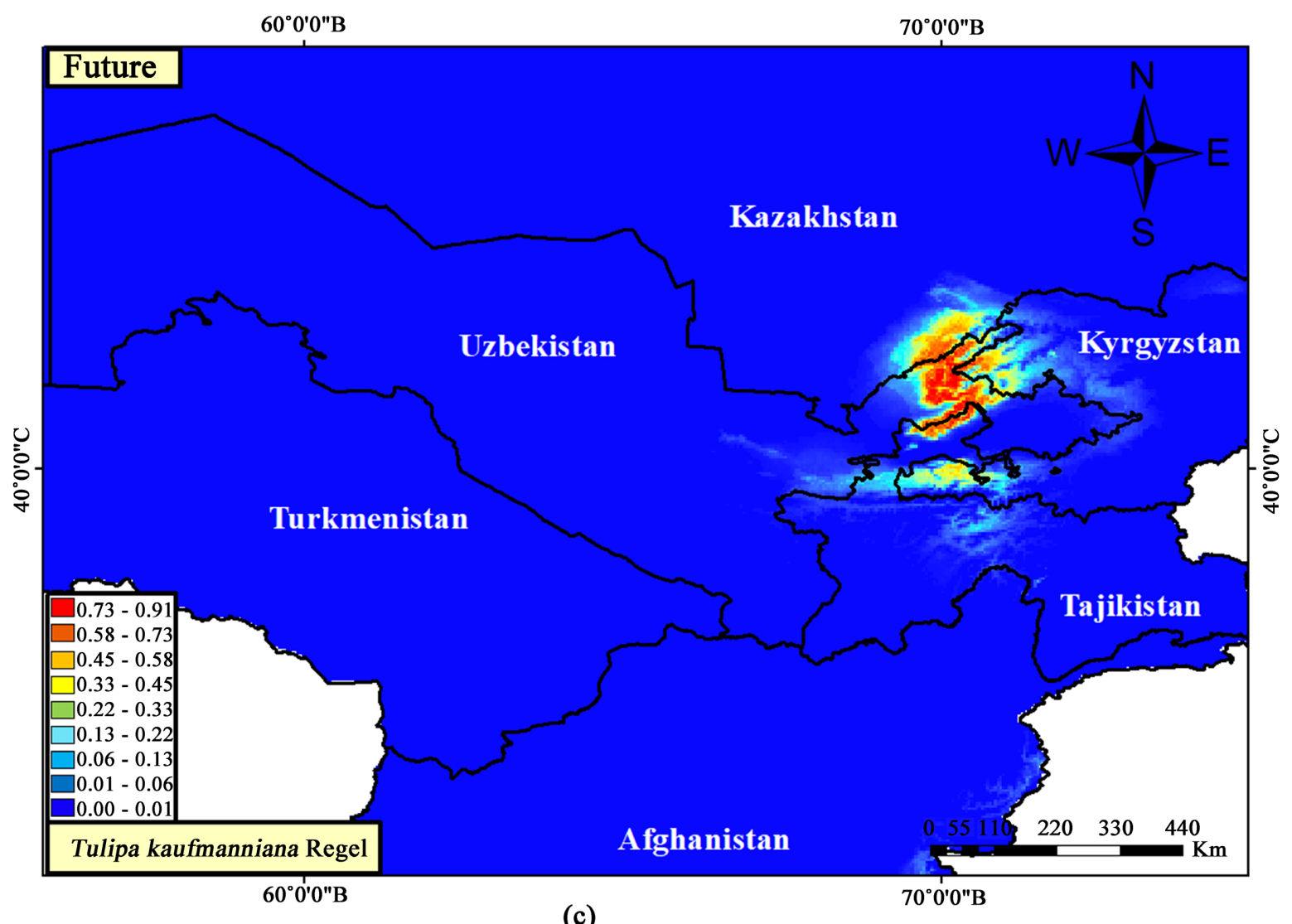

Figure 4. Species distribution range ((a) past, (b) current, (c) future).

the relative contribution of environmental variables to the potential distribution area is shown in different tables. In the MaxEnt program, a number of indicators are used to assess the feasibility of a species prediction model. There are two different types of errors in modeling: omission-the presence of the quality of absence and prediction contribution, and commission-absence as a presence, prediction contribution. In this case, the graph exposes (diagram 1) that the red curve (fraction of background predicted) represents the contribution of "background" points in the lower variable cumulative boundary included in the modeled distribution region. The blue line-omission on training samples, describes the performance of the model and shows the contribution of the point of existence that extends beyond the boundary of the region, from the bottom to the top of the boundary value, limiting the prediction of the existing region. Blue line-omission on tasting samples. Black line-Predicted omission (Figure 4).

The Area Under the curve (AUC) diagram (Figure 5) formed in MaxEnt of the T. kaufmanniana Regel distribution zone consists of three lines. The red curve (Traning data) line delimits the AUC, and the closer this line is to the upper left corner, the larger the area under the curve, and the better the model predicts availability points. The blue curve (Test data) line indicates that the model being studied is well described by the model. The black line is straight (Random Prediction) delimiting the area, the discrimination below is not higher than chance. 

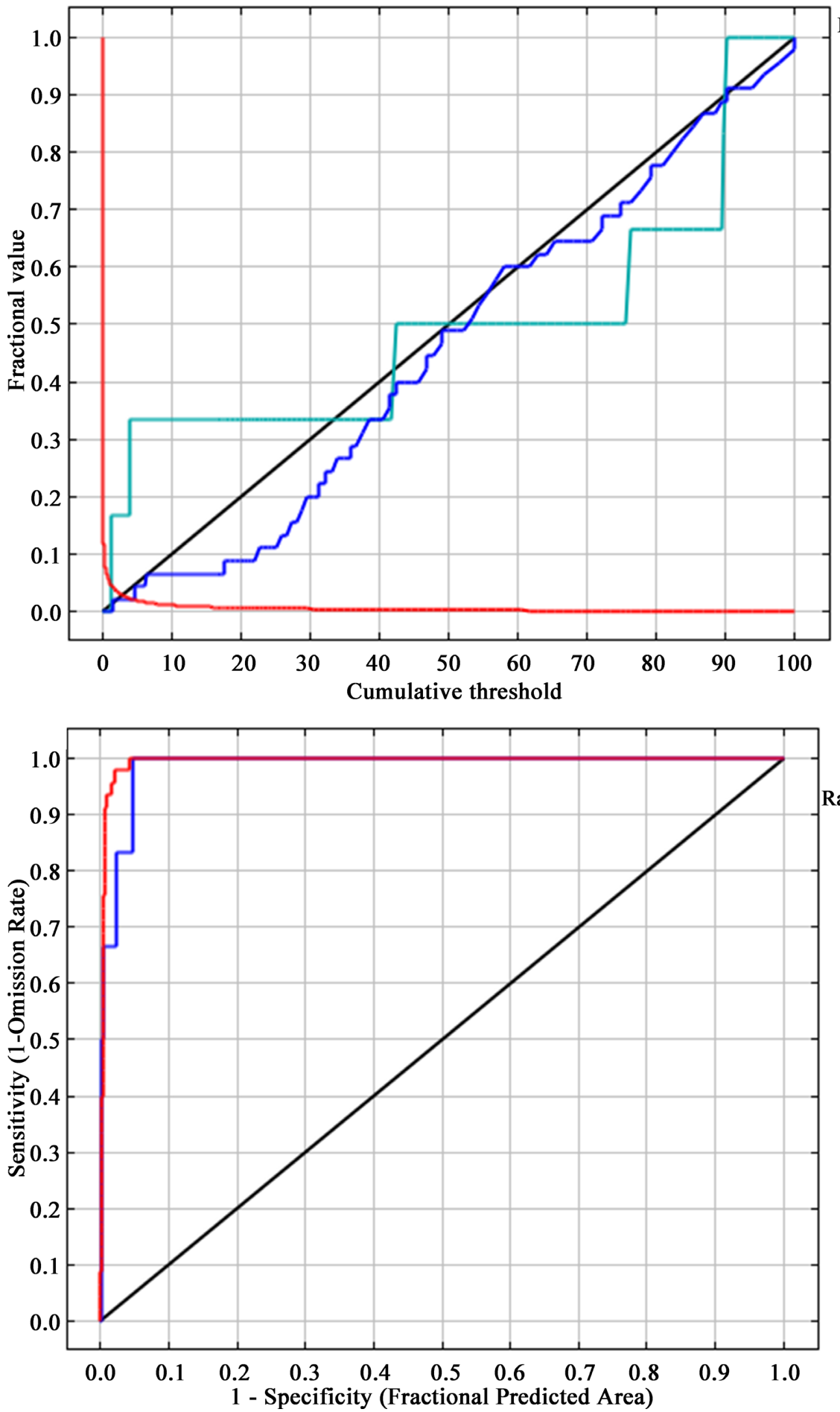

Figure 5. Feasibility of a species prediction model.
Fraction of background predicted Omission on training samples Omission on test samples Predicted omission
Training data $(\mathrm{AUC}=0.995)$ "

Test data $(\mathrm{AUC}=0.987)$. Random Prediction $(\mathrm{AUC}=0.5)$

In this case, the model shows the climatic needs of the species, not the location of the species, which depends on many other conditions other than climate.

\section{Conclusion}

Data from the T. Kaufmanniana Regel show that the main distribution area of 
the species has been proven to be around the boundaries of the Tien-Shan mountain range. Climatic factors that are optimal for the species have been noted to be adequate temperatures and annual rainfall. The results of modeling are used to analyze rare and endangered species, to conduct long-term monitoring of them and to determine the ecological optimum of the species. Determining the ecological optimum of the species will allow for the successful introduction of these species in the future. In addition, data on rare and endangered species will be used in future editions of local Red Books.

\section{Conflicts of Interest}

The authors declare no conflicts of interest regarding the publication of this paper.

\section{References}

[1] Bochantseva, Z.P. (1961) Areas of Modern Forming of Tulips in Central Asia. Trudy Tashgu, Issue 187. Biological Sciences. Tashgu, Tashkent, 272-275.

[2] Bochantseva, Z.P. (1962) Tulips. Akad. Sciences, Tashkent, Uz. SSR. 407 p.

[3] Tajiboev, K.Sh. and Kadyrov, R.U. (2010) Tulips of Uzbekistan. Shark, Tashkent, $224 \mathrm{p}$.

[4] Baranova, M.V. (1999) Bulbous Plants of the Lily Family. Nauka, Saint Petersburg, 229.

[5] Sharipov, A. and Pratov, O. (1997) Tulips. National Encyclopedia of Uzbekistan. State Scientific Publishing House, Tashkent, $141 \mathrm{s.}$

[6] Ivashchenko, A.A. (2005) Tulips and Other Bulbous Plants of Kazakhstan. Two Capitals, Almaty, $192 \mathrm{p}$.

[7] Pechenitsyn, V.P. (2008) Embryology of Central Asian Tulipa Species. Tashkent, 150 p.

[8] Abduraimov, A.S. (2017) Biological Characteristics and Status of Cenopopulations of the Tulipa L., Spread in the Kyzylkum Desert: Biol. Science. Abstract of Dissertation $(\mathrm{PhD})$, the Dis., Tashkent, $43 \mathrm{p}$.

[9] Tojibaev, K. and Beshko, N. (2015) Reassessment of Diversity and Analysis of Distribution in Tulipa (Liliaceae) in Uzbekistan. Nordic Journal of Botany, 33, 224-234. https://doi.org/10.1111/njb.00616

[10] Red Book of Uzbekistan (2019) Plants and Fungi. Chinor Publishing House, Tashkent, $256 \mathrm{p}$

[11] Olonova, M.V. and Gudkova, P.D. (2021) Creating a Bioclimate Model of Species. Methodical Instruction on Assignment and Their Implementation for Practical Work T. 4-15.

[12] Free and Open Access to Biodiversity Data. https://www.gbif.org

[13] Phillips, S.J., Anderson, R.P. and Schapire, R.E. (2006) Maximum Entropy Modeling of Species Geographic Distributions. Ecological Modeling, 190, 231-259. https://doi.org/10.1016/j.ecolmodel.2005.03.026

[14] Phillips, S.J. and Dudík, M. (2008) Modeling of Species Distributions with Maxent: New Extensions and a Comprehensive Evaluation. Ecography, 31, 161-175. https://doi.org/10.1111/j.0906-7590.2008.5203.x 
[15] Abduraimov, O.S., Shomurodov, H.F. and Abduraimov, A.S. (2017) Distribution Pattern and State of Coenotic Population of Tulipa lehmanniana Merckl. in Kyzylkum Desert Conditions (Uzbekistan). American Journal of Plant Sciences, 8, 288296. https://doi.org/10.4236/ajps.2017.82020

[16] Abduraimov, O.S., Shomurodov, H.F. and Daniyarov, S.A. (2018) The Current State of Cenopopulation of Tulipa micheliana Hoog in Uzbekistan. American Journal of Plant Sciences, 9, 1725-1739. https://doi.org/10.4236/ajps.2018.98125

[17] https://www.worldclim.org 